of the organizers, the rest became available for distribution only after the proceedings had started.

It would require a separate article to assess the encyclopædic value of these papers, record their contributions to routine, point to new problems which are raised and new approaches which are suggested. The present review must limit itself to the Conference and its outcome.

The main topics discussed by the various sections may be briefly described by abbreviated versions of the recommendations. The recommendation of Section (1) refers to the question of authorities responsible for publicizing and explaining the principles and practice of the Universal Decimal Classification. Among the specific tasks recommended for immediate attention, the following are especially mentioned : compiling and circulating a list of Universal Decimal Classification users; securing distribution of the new cumulative Extensions and Corrections to the Universal Decimal Classification; preparing a short edition based on the latest available Dutch "Verkorte Uitgave" ; assisting in the revision of specific Universal Decimal Classification sections with special reference to the preparation of the fourth (English) and fifth (French) editions ; preventing the distribution of unauthorized editions. Multilingual editions were also recommended by the Section.

The deliberations of Section (2) were centred on the comparative merits of the different micro-techniques, and the recommendations limited to matters of format and terminology. Questions of method and policy, touched upon in some of the printed papers, did not come up for discussion. Some of the delegates found fault with the exhibition of technical devices, organized for the Conference at the Istituto di Matematica, because it did not offer the ultimate solution of their problems. While the scope of the exhibition did not differ greatly from similar shows previously displayed in Britain or elsewhere, attention might be directed to a series of microcard readers, at different pricelevels, from the United States, and to a prototype of a simple camera of Italian make for taking flat microfilm of the 'fiche' or sheet type. This type of film, incidentally, is gaining popularity (as might have been foreseen) for purposes where convenience of handling, filing, and so on, are more important than speed of initial operation.

Section (3) emphasized the need for better dissemination of technical information contained in patent specifications, recommended the drafting of standards for citations and descriptions of references, and discussed the possibility of standardizing the bibliographical and formal presentation of abstracts.

The discussions of Section (4) resulted in a recommendation urging universities and scientific institutions to have academic writings which they deem important published or reproduced by an appropriate process in numbers sufficient for the needs of exchange purposes, and noting, further, that such exchanges should not be based on the monetary value of the document. The Section also suggested that other scholarly production existing only in manuscript form should be listed in analytical bibliographies with indication of the depository library or documentation centre able to supply copies upon demand.

Much thought was devoted by Section (5) to the problem of training documentalists. It was, inter alia, suggested that archives and museums should be invited to participate in the deliberations hitherto attended mainly by librarians; that professional education should be regionalized wherever such development might be considered useful; that prototype programmes of education in documentation should be discussed in 1952, and a conference of persons responsible for the training of librarians and documentalists should be convened for 1953. It was finally suggested that, in response to an international need, documentation should be recognized as a profession in its own right, and that a professional statute for documentalists should be drawn up.

Section (6) recommended a survey of the different systems of classification now used in libraries, archives, documentation centres and government offices, and expressed the hope that possibilities of co-ordinating the different systems might be explored.

The recommendations of Section (7), worked out in considerable detail, may be summarized as follows. The specialized dictionaries hitherto available cover no more than a small part of all technical subjects and languages. Most of these dictionaries are technically inadequate from the user's point of view. Production of specialized vocabularies should be organized on international and national levels, and should be preceded by preparatory tasks under these headings : standardization of terminological and lexicographical principles ; compilation of terminological bibliographies and directories of organizations dealing with terminological questions; compilation of bibliographies of classifications and of directories of organizations dealing with classifications. The various tasks should be assigned to specialized agencies, and only the international co-ordination should remain centralized.

The full text of the recommendations-of which only the gist could be given here-was formally adopted by the plenary session and submitted to the Council of the International Federation of Documentation, of which M. Arne Møller (Denmark) is now president.

The working programme of the Conference was pleasantly interrupted by a number of social engagements. A special and unexpected event was the audience granted to the participants of the Conference by the Pope at the Palazzo Pontificio di Castel Gandolfo, the Pope's private residence in the Alban Hills. His speech, in French, in which he summed up the problems confronting documentation, was afterwards published in the Osservatore Romano on September 21. Lucia MoHoly

\section{STATISTICAL METHODS IN CHEMISTRY}

$\mathrm{O}^{\mathrm{N}}$ October 25, the London and South Eastern Counties Section of the Royal Institute of Chemistry held a discussion on "The Application of Statistical Methods to Chemistry", This was planned as a supplement to the course of lectures on statistical methods given for the Institute by Mr. D. R. Read in September 1950. Under the chairmanship of Dr. C. W. Herd, more than two hundred members assembled to hear four speakers give prepared answers to questions that had been submitted and to inquire for further information on special points.

In the first of the four short papers, Dr. E. C. Wood described how careful attention to experimental design can benefit the chemist. He emphasized particularly the difference between the 'classical' approach of testing each relevant factor in turn, in 
order to assess its effect on a quantity to be determined, and the modern method of factorial design. He showed that, when the best value for one factor in a chemical reaction depends upon the level of others, the classical method might fail to discover the optimal conditions in respect of the several factors. The alternative of testing a carefully selected set of combinations of levels of all the important factors may give more information on the optimal, from a smaller total number of observations yet with increased assurance that relevant interactions of factors had not been overlooked. Dr. O. L. Davies supplemented Dr. Wood's remarks by illustrating how, when tests of combinations of factors are to be made in succession rather than simultaneously, recent developments of special designs in the 'steepest ascent' technique can be made to yield information on the optimal even more economically. Dr. D. J. Finney later directed attention to the importance of randomization and the true independence of replicate observations in order that valid assessments of experimental error might be made.

In the second paper, Dr. D. J. Finney was concerned with the problem of choosing a form of curve to represent experimental data. $\mathrm{He}$ said that if mathematical theory can suggest the appropriate type of curve, this should be used and statistical theory would then show how to estimate it. If not, the experimenter should ask himself whether he really wants a curve, and should not try to fit one unnecessarily. Various transformations might be tried in order to bring a freehand curve into approx imately linear form; but data additional to the first experiment would be needed in order to estimate the relationship as well as to infer its form. For smoothing and interpolation, as distinct from study of the fundamental relationship, the precise form of curve is often unimportant, as, for example, in bioassay. He warned particularly against extrapolation and against confusion of purpose between a 'utilitarian' curve and one ropresenting fundamental properties of the material. Mr. D. R. Read illustrated the occasional need for fitting a complicated curve.

Dr. Davies had been asked to discuss a particular question relating to the sampling of tablets required to conform to a specification of density. He spoke of the need for care in the selection of a representative sample from each batch of tablets. This sample must be large enough to give reasonable confidence that a bad batch will not be accepted as good, nor will a good batch be rejected as bad on account of sampling variations. He gave details of two statistical tests, both sequential. The first involves classification of a random succession of tablets as 'good' or 'bad' until evidence on the proportion of good ones enables a decision to be taken. The second, using a sequential $t$-test, requires measurement of the density of each tablet instead of mere classification, but on an average would permit a decision to be reached from examination of about half as many tablets; the choice between the two methods must depend upon the relative costs of classifying a tablet as good or bad and measuring its density. For either test, the tablets in the whole sample selected must be examined in random order. Dr. Wood mentioned the dangers of uncritical use of sequential sampling.

Mr. Read's paper related to the rejection of apparently anomalous outlying members of a series of chemical determinations. He said that, though somo discrepant observations might justifiably be rejected because of known accidents or anomalies during the experiments that produce them, the chief difficulty relates to whether (and when) observations might be rejected purely on the internal evidence that they had been affected by exceptionally large 'random' errors. He held that even in these circumstances an observation may occasionally be legitimately rejected, in the light of common sense, knowledge of relevant circumstances, and demonstration that its value is almost certainly too discrepant to be due to chance. He presented several statistical tests recently proposed for assessing the evidence for significant aberrancy in outliers, and suggested comparing their merits in terms of the probabilities that they would discover the contamination of a set of observations by an accidental error of specified size. He considered that one or other of these tests might be of real practical value, but that neither should be uncritically adopted. Dr. Finney and Dr. Wood later expressed doubts about the general utility of statistical tests for making what is basically a moral decision : whether or not to regard a particular observation as the product of accident, incompetence, or lunacy (rather than as a fair representation of natural deviation from a norm), on the sole basis of the internal evidence of the data. Dr. Wood nevertheless advised that long experience of the type of variation normally encountered with certain material might justify the experimenter in attributing an occasional aberrant value to an un. suspected accident.

The chairman then reviewed the papers. Before opening the meeting to general discussion, he commented on two matters: the frequent need for a decision, at one moment of time, on the sampling procedure for a bulk of material (such as a consignment of iron ore) that would thereafter not be available for further study, and the permissibility of rejecting a measurement about the validity of which an expert analyst is suspicious even though he cannot assign a reason. In reply, Dr. Davies emphasized the need for treating every sampling problem on its merits, in the light of knowledge of the material and its variability; the statistician could not devise a good scheme without preliminary study, possibly based upon a pilot sample. Mr. Read pointed out that only the experimenter could decide whether his 'hunch' justified him in rejecting the observation immediately or in making further experiments and applying a statistical test for rejection.

The questions and discussion that followed were of great interest, but can be reported only briefly. Many raised further points about the rejection of outliers. Mr. A. L. Bacharach pointed out that Dr. Wood's suggestion of deciding on rejection from past experience of the reasonable variation in the material under test is essentially an appeal to a statistical criterion (or else a doctrine of expediency). Dr. Finney suggested that control charts might be adapted to the evaluation of past experience in relation to rejection, and Mr. Sears said that the Institute of Petroleum has recommended something of this kind. Mr. Battersby mentioned that, in the analysis of bauxite, if two different analyses are seriously discrepant, it is customary to make several additional analyses and to average all results without rejection. Mr. Haslam spoke of the need for checking the effect of the personal factor, by making. analyses or other measurements on material the true nature of which is known to others but not to oneself. Mr. Stevens commented on the danger of a spurious appearance of precision when publica- 
tion of an analytical process in a standard work of reference is based upon multiple analyses in one laboratory: other workers, whose laboratories are possibly less exactly controlled, may show much poorer agreement through no fault of their own. Dr. Davies agreed that different laboratories often show appreciable differences in standard analyses. Dr. Finney emphasized the need for remembering that any standard deviation relates to the variation from a particular set of causes, and may well fail to characterize the dispersion of actual observations when additional sources of variation are introduced. Mr. Bacharach argued strongly that new standard analytical techniques ought to be studied collaboratively in several laboratories; he also reminded the audience that outliers should never be rejected without examination of causes, for observations that were apparently anomalous have often been the start of great new developments. Mr. Smart quoted an instance of a set of two hundred observations that conformed excellently to a normal (Gaussian) distribution if six extreme values were rejected; Dr. Finney maintained that this in itself did not justify the rejection unless there were strong a priori reasons for believing that the true distribution was normal.

Mr. Senior asked for advice on the sampling of very valuable material, for which the actual cost of the portion used in analysing a sample might be important. Dr. Davies suggested that the difficulty could be removed by the chemist devising techniques for the analysis of very small quantities. Dr. Wood pointed out that the policy to be adopted must be determined on economic grounds: if decisions of great monetary or other importance depend upon reliable analytical information, even large expenditure on sampling may be a desirable measure of insurance against grave errors.

Several other inquiries related to the sampling of continuous processes. Mr. Hewitt asked about the frequency with which indicators of a process ought to be read in order to provide adequate evidence of whether or not the process is in control. Mr. Soper suggested standard quality-control practices of intensifying observations when the control is under suspicion. Dr. Davies said that observations must be frequent enough to detect fluctuations of a size that would be important to the process, and that only by knowledge of the process could any more exact guidance be given. Dr. Wood warned against dependence on observations at regular intervals of time, regular in relation to shifts, or in any other way likely to be related to periodicities in the process, since periodic changes might impair the validity of estimates of variability; Dr. Finney directed attention to the non-independence of successive observations on a continuous process and the possibly autoregressive character of the errors.

In reply to a question from Mr. Berkovitch about the number of levels of various factors to be used in a factorial experiment for the estimation of optimal conditions, Dr. Wood suggested that three or four levels of each factor usually suffice. Dr. Finney thought that many factors at two levels each might be used in a preliminary trial, and those that were found most important might later be tested more intensively, at three or four levels each, over a narrower range. Dr. Davies again emphasized the great advantages of a sequential steepest-ascent investigation where this is practicable. Mr. Berkovitch also suggested that extrapolation from a set of observations, in spite of its logical and theoretical flaws, may legitimately be used to indicate useful lines for further experimentation; Dr. Finney fully agreed that this is valuable and certainly permissible provided that the extrapolations are not regarded as established before experiment has confirmed or refuted them. Mr. Soper suggested that time ought often to be regarded as a factor in an investigation, and all experiments repeated at two or three distinct times, since extrapolation in time is essential to the usefulness of any inferences drawn.

\section{J. FINNEY}

\section{NATIONAL INSTITUTE FOR RESEARCH IN DAIRYING, SHINFIELD REPORT FOR 1950}

T

HE farm must obviously be the site of much of the experimental work of a research organization such as the National Institute for Research in Dairying, Shinfield, and in the annual report for 1950 , which has recently been published*, it is made clear that the farm is the important background of much of the laboratory work. The Institute has two farms, covering about seven hundred acres, with more than two hundred head of cattle-largely Shorthorns but with some Friesians and Guernseys. As in many other agricultural research centres, some devolopments, particularly those involving buildings, are unavoidably slow, and preparation for them occupies a lot of the time of the staff. But within these limits the work of the farms is very progressive, including the implementing of a well-defined breeding programme and the careful cataloguing of all records that may conceivably be needed in the interpretation of experimental results.

Besides maintaining the essential work and records of the farms as such, the Dairy Husbandry Section has a good deal of experimental work to its credit, including a continuation of studies of the rates of milking, of the suitability of certain fodder crops for milk production, and various experiments on the rate of growth and milk yields of pigs.

For some years the Institute has been concerned with factors affecting the efficiency of the use of food by ruminants, and the experimental work has lately been much facilitated by the design of a harness for the satisfactory separation of the urine and the fæces of the dairy cow. Much of this work has since been published. In the recent work it has been found that the softening of finely divided hay (as opposed to long hay) by grinding in the mouth reduces the ability to regurgitate. Initiation of the regurgitation reflex his, however, sometimes been brought about by appropriate hand-scratching.

It has been found that diets low in roughage cause a reduction in fat yield but do not affect the percentage of non-fatty solids. The properties of butter were affected, too, by low roughage diets, the butter having a higher percentage of unsaturated acids and a low softening point.

The report for last year called in question the use of lignin as a 'reference' substance in studying rates of digestion. The validity of using lignin depends

* University of Reading: National Institute for Research in Dairying. Report for 1950 . Pp. 103. (Shinfteld: National Institute for Research in Dairying, 1951.) 38 . 